\title{
A Neural Code for Looming and Receding Motion Is Distributed over a Population of Electrosensory ON and OFF Contrast Cells
}

\author{
Stephen E. Clarke, ${ }^{1}$ André Longtin, ${ }^{1,2}$ and Leonard Maler ${ }^{1}$ \\ ${ }^{1}$ Departments of Cellular and Molecular Medicine, and 2Physics, University of Ottawa, Ottawa, Ontario K1H 8M5, Canada
}

\begin{abstract}
Object saliency is based on the relative local-to-background contrast in the physical signals that underlie perceptual experience. As such, contrast-detecting neurons (ON/OFF cells) are found in many sensory systems, responding respectively to increased or decreased intensity within their receptive field centers. This differential sensitivity suggests that $\mathrm{ON}$ and OFF cells initiate segregated streams of information for positive and negative sensory contrast. However, while recording in vivo from the ON and OFF cells of Apteronotus leptorhynchus, we report that the reversal of stimulus motion triggers paradoxical responses to electrosensory contrast. By considering the instantaneous firing rates of both $\mathrm{ON}$ and $\mathrm{OFF}$ cell populations, a bidirectionally symmetric representation of motion is achieved for both positive and negative contrast stimuli. Whereas the firing rates of the individual contrast detecting neurons convey scalar information, such as object distance, it is their sequential activation over longer timescales that track changes in the direction of movement.
\end{abstract}

Key words: distributed coding; electrosense; labeled lines; looming; ON/OFF cells; spike-frequency adaptation

\section{Introduction}

The ability to measure sensory contrast is a cornerstone of perceptual experience: by encoding coherent patterns of contrast, nervous systems can assemble spatiotemporal representations of distinct stimuli in their environment. To detect relative differences in these physical signals, many diverse sensory systems possess two subsets of modality-specific neurons that are selective for either increased or decreased intensity within their receptive field (RF) centers. Traditionally termed ON and OFF cells in the vertebrate (Schiller, 1992) and invertebrate (Joesch et al., 2010) visual systems, these distinct classes have been documented in other sensory modalities including audition (Tian et al., 2013) and chemoreception (Lockery, 2011). Under static conditions, ON retinal ganglion cells (RGCs) are excited by increased illumination at their RF centers (positive contrast), whereas OFF RGCs are excited by decreased illumination (negative contrast). Conversely, ON RGCs are notably suppressed by negative contrast at their RF centers, and OFF RGCs are suppressed by positive contrast. These classic observations suggest that ON/OFF cells act as "labeled lines," which initiate parallel pathways for positive and negative visual contrast information (Schiller, 1992). However,

\footnotetext{
Received Nov. 27, 2013; revised March 11, 2014; accepted March 13, 2014.

Author contributions: S.E.C., A.L., and L.M. designed research; S.E.C. performed research; S.E.C. analyzed data; S.E.C., A.L., and L.M. wrote the paper.

S.E.C. was supported by an Ontario Graduate Scholarship and S.E.C., L.M., and A.L. were supported by the Natural

Sciences and Engineering Research Council of Canada and the Canadian Institutes of Health Research.

The authors declare no competing financial interests.

Correspondence should be addressed to Stephen Clarke, University of Ottawa, 451 Smyth Road, Room 2234, Ottawa, 0N K1H 8M5, Canada. E-mail: stephen.elisha.clarke@gmail.com.

DOI:10.1523/JNEUROSCI.4988-13.2014

Copyright $\odot 2014$ the authors $\quad 0270-6474 / 14 / 345583-12 \$ 15.00 / 0$
}

Geffen et al. (2007) provide preliminary evidence that ON/OFF cell contrast coding is not as simple as it seems.

A population of ON/OFF neurons operate in the electrosense of gymnotiform fish, such as Apteronotus leptorhynchus (Bastian et al., 2002). During electrolocation, these fish sense objects as local amplitude modulations to a self-generated electric field: the electric organ discharge (EOD; Chacron et al., 2011). These changes in EOD amplitude are encoded by cutaneous electroreceptors, whose afferents project topographically to pyramidal cells in the electrosensory lateral line lobe (ELL; Krahe and Maler, 2014). E (ON) type pyramidal cells receive direct excitatory input from the electroreceptor afferents (Berman and Maler, 1998) and respond to increased EOD amplitude at their RF centers (Bastian et al., 2002). The same electroreceptor afferents also project indirectly to I (OFF) cells via local inhibitory interneurons (Berman and Maler, 1998). Like the visual system, disynaptic inhibition implements a sign inversion on the input, creating electrosensory contrast neurons that are selective for decreases in EOD amplitude (Bastian et al., 2002). E- and I-cell pairs are arranged in columns and share joint receptive fields, which display the same center-surround organization as the iconic ON/OFF RGCs (Schiller, 1992; Krahe and Maler, 2014). The functional analogy between the electrosensory and visual system ON/OFF cells has been previously emphasized (Maler et al., 1981; Chacron et al., 2011), and until now, E and I pyramidal cells have been thought to act as strict labeled lines for positive and negative contrast.

By presenting motion stimuli that reverse direction within their RF, we analyzed the role of the electrosensory ON/OFF cells as the neural basis of sensorimotor behaviors, such as the electromotor response (Heiligenberg, 1973a) and prey capture (MacIver et al., 2001). We show that labeled lines are too rigid a coding scheme for electrolocation and the perception of motion. 


\section{Materials and Methods}

As previously described (Marsat et al., 2009), surgery was performed on adult fish (male and female) to expose the caudal cerebellum overlying the ELL. All surgical procedures were reviewed and approved by the Animal Care Committee at the University of Ottawa. Fish were mounted into a large tank of water $\left(27^{\circ} \mathrm{C} ; 100-120 \mu \mathrm{S} / \mathrm{cm}\right)$ and a custom holder was used to stabilize the head during recordings. Their tails were tethered in position with thread to avoid any significant displacement of the body due to the hydromechanical effects caused by looming/receding motion. The fish were monitored for signs of stress and allowed time to acclimatize before commencing our stimulus protocols.

Extracellular recordings were obtained from pyramidal cells of the centrolateral map of the ELL (Krahe and Maler, 2014). This map was chosen because its neurons respond well to object movement (Krahe and Maler, 2014) and have large RFs that are easy to locate using a local stimulus dipole (Maler, 2009). After locating a cell's RF center, we classified it as E or I based on its response to EOD amplitude increases and decreases respectively (Bastian et al., 2002). We then mapped out the RF center, which yielded spatial spreads consistent with anatomical estimates previously generated for the centrolateral map (Maler, 2009). The baseline firing rates of the recorded $\mathrm{E}$ and I pyramidal cells $(9.3-20.2 \mathrm{~Hz}$; $\left.N_{\mathrm{E}}=15, N_{\mathrm{I}}=10\right)$ demonstrate they are the superficial and intermediate types (Bastian and Courtright, 1991; Krahe and Maler, 2014). Next, according to cell type, a plastic or brass sphere was mounted to an electromechanical positioner, controlled by outputs from our recording software. The selected sphere was aligned with the cell's RF center along the lateral body axis, and stimulation consisted of 10 repetitions of a continuous loom/recede sequence at a speed of $2 \mathrm{~cm} / \mathrm{s}$, chosen as an intermediate value from locomotion studies (Heiligenberg, 1973b; MacIver et al., 2001) and prey escape behaviors (O'Keefe et al., 1998). This stimulation protocol was then repeated with the other sphere. In some cases, we were able to simultaneously record from E/I cell pairs and directly compare their differential responses to object motion. For 23 of 25 pyramidal cells used in this study, the same looming/receding sequence was repeated with a $7 \mathrm{~s}$ pause at the skin before reversing and returning to the initial position.

We also studied the responses of $\mathrm{E}$ and I cells to motion reversal within their RFs for stimuli moving parallel with the longitudinal body axis. For these experiments, the spheres were positioned at a fixed lateral axis distance of $0.5 \mathrm{~cm}$, and, starting $3 \mathrm{~cm}$ caudal of the RF, traveled into its center followed by reversal and withdrawal back to the initial position $\left(N_{\mathrm{E}}=3, N_{\mathrm{I}}=2\right)$.

Estimation of stimulus-induced firing rates is not a trivial problem, especially since our dynamic stimuli drive nonstationary interspikeinterval (ISI) statistics in the ELL pyramidal cells. To estimate the underlying rate responses, we initially applied a smoothing algorithm that optimally selects a variable kernel bandwidth, determined locally in time over the course of our looming/receding stimulus (Shimazaki and Shinomoto, 2010). This method produced response trends that are readily grasped, making effective visual aids. Although partially due to averaging variable responses to the repeated stimulus, the peak firing rates experienced during bursting are largely underestimated by the algorithm, which cannot fully capture the abrupt transitions between different modes of spiking (e.g., burst spiking to quiescence). This is not entirely surprising since the algorithm relies on the premise that the ISIs are Poisson distributed; although ELL pyramidal cell spiking can be modeled as a renewal process, burst spiking significantly alters the ISI distributions. Therefore, for our statistical analysis of the firing rate data, we used a fixed $30 \mathrm{~ms}$ Gaussian kernel that produced peak firing rate responses consistent with previous studies on burst spiking in ELL pyramidal cells (Oswald et al., 2004; Marsat et al., 2009). For each cell, responses to 10 consecutive loom/recede sequences were averaged together to obtain the firing rate (FR), which was normalized as a proportional change in baseline firing rate $(\mu F R)$ :

$$
\Delta F R=\frac{F R-\mu_{F R}}{\mu_{F R}} .
$$

These values were then converted to a stimulus-induced, percentage increase or decrease in firing rate $(\% \Delta F R)$.
For recordings from the primary electroreceptor afferents, glass micropipettes (filled with $3 \mathrm{~m}$ potassium acetate; resistance 90-120 M $\Omega$ ) were advanced through the cerebellum to take extracellular recordings from the electroreceptor nerve in the deepest layer of the ELL's centrolateral map $(N=25,7$ fish). While recording in vivo, we directly modulated the EOD amplitude with custom-made stimulus dipoles, to recreate the electrosensory signals generated at a pyramidal cell's RF center by the looming/receding spheres (Clarke et al., 2013). For the sake of consistency with the pyramidal cell analysis, firing rates were computed by convolving the spike train data with a $30 \mathrm{~ms}$ Gaussian kernel. Averaged firing rates were then determined from $10-15$ repeated presentations of our looming/receding motion signal.

The large range of baseline firing rates of the electroreceptor afferents produce noticeable bias in the $\% \Delta F R$ measure used for the ELL pyramidal cells. Consequently, for each afferent, we use a measure of change that is normalized to the largest stimulus-induced difference between the cell's response and it baseline firing rate. We implicitly use the maximum definition for the brass stimulus and the minimum definition for the plastic stimulus:

$$
\Delta F R_{\text {norm }}=\frac{F R-\mu_{F R}}{\max [F R]-\mu_{F R}} \text { or } \Delta F R_{n o r m}=\frac{F R-\mu_{F R}}{\min [F R]-\mu_{F R}} .
$$

The analysis in Figure 4 is the only time the $\Delta F R_{\text {norm }}$ measure is applied to the looming/receding pyramidal cell data, because it allows for direct gain comparison with the electroreceptor afferent data. It should be noted that electroreceptor afferents with extreme baseline firing rates $(<150 \mathrm{~Hz}$ and $>400 \mathrm{~Hz})$ were excluded from the analysis due to firing rate saturation effects in the near-field.

We modified a preexisting E-cell model (Noonan et al., 2003), to determine whether it could explain the results observed in response to motion reversal. The model was designed to capture the nonlinear interactions between a pyramidal cell's soma and its proximal dendrites, which generates burst spiking like that observed in vitro. The parameters used in the model were left unchanged; only the bias current and stimulus gain were manipulated to generate baseline and peak firing rates comparable to those observed in vivo. In addition, we added a source of exponential spike frequency adaptation to this model, which was calibrated at the physiological adaptation time constant of $0.2 \mathrm{~s}$ obtained by Krahe et al. (2008) for the CLS map.

Given a single output spike train from the model, convolution with the $30 \mathrm{~ms}$ Gaussian kernel results in choppy estimation of the firing rate. To obtain smooth firing rates from the deterministic spiking model, different realizations of Gaussian noise $\left(\rho(t)=4 \cdot e^{-t^{2}}\right)$ were added to the subthreshold membrane potential dynamics. The resulting jitter in the model spike times better resembles the noisy responses of $\mathrm{E}$ cells and also allows us to average over many individual trials to obtain a smooth firing rate estimate after convolution with the Gaussian kernel. We did not perform any simulations for I cells because their local circuitry is far more complex (Maler et al., 1981) and has not been adequately modeled.

\section{Results}

Consistent with contrast coding definitions, when nonconducting objects (e.g., rocks) move across the sensory surface of $A$. leptorhynchus and into the RF of an E/I pair, the I cell responds to the negative contrast with an increase in firing rate, whereas the $\mathrm{E}$ cell is suppressed. Likewise, positive contrast caused by conducting objects (e.g., plants and prey) moving into the RF of an E/I pair, evokes an increased firing rate from the E cell, whereas the I cell's activity is depressed (Bastian, 1981; Chacron et al., 2009). During navigation, objects in the environment moving toward the body (looming) are a common occurrence. We have shown that a looming, positive-contrast inducing stimulus causes the firing rate of the electroreceptor afferents to increase, which encodes changes in object distance (Clarke et al., 2013). In agreement with known physiology, the positive contrast is expected to evoke a strong response in the E cells, while inhibiting I-cell 
activity. Likewise, a looming, negative-contrast inducing stimulus will cause decreases in the electroreceptor afferent firing rates, which lead to strong I-cell responses and a decreased firing rate in the E cells. Therefore, it appears that looming object motion generates responses that adhere to the conventional definitions of contrast coding.

Looming stimuli are of obvious importance in the visual system and have been extensively studied (Fotowat and Gabbiani, 2011). Interestingly, far less attention has been devoted to how the visual system might encode receding movements, even though such stimuli occur naturally. In the electrosense, both looming and receding signals are readily processed by gymnotiform fish, as evidenced by the electromotor response designed by Heiligenberg (1973a). In this sensorimotor task, a fish actively tracks the motion of swinging plastic rods (nonconductive objects) that loom and recede relative to its body. Like the visual system's optomotor response, the electromotor response relies on the system's ability to discriminate features of the moving stimulus, such as distance, speed, and the direction of movement, to initiate appropriate motor commands (Heiligenberg, 1973a). Therefore, we designed our looming/receding stimulus protocols with both negative- and positive-contrast inducing stimuli (plastic spheres and brass spheres) to mimic conditions of Heiligenberg's experiments and the natural behaviors that inspired them (Fig. 1A).

\section{Responses of I and E cells to looming/receding trajectories}

I cells respond with an increased firing rate as the plastic object looms toward their RF centers (Fig. $1 B$, top). On average, the peak firing rate of I cells increased by $770.44 \pm 112.66 \%$ from baseline levels and was marked by strong bursting. ELL pyramidal cells have an intrinsic burst generating mechanism that is activated by low-frequency signals (Krahe and Gabbiani, 2004), such as those induced by looming motion (Clarke et al., 2013), and which generates ISIs $<10 \mathrm{~ms}$ (Oswald et al., 2004; Marsat et al., 2009). Using this criterion, we sorted burst spikes from tonic spikes, allowing us to calculate the fraction of all action potentials contributed by the burst mechanism (Oswald et al., 2004). The burst fraction $(\mathrm{BF})$ of I cells increased dramatically when the plastic sphere drew close to the fish's skin, from $0.21 \pm 0.09$ to $0.78 \pm 0.13$.

I cells were not excited by the negative contrast created by the receding plastic sphere. Instead, upon direction reversal, I cells immediately stopped bursting (BF: $0.026 \pm 0.12$ ) and their firing rates dropped significantly to $-91.05 \pm 15.28 \%$ of baseline (Fig. $1 B$, top), calculated as an average rate over the first $0.5 \mathrm{~cm}$ of withdrawal. In many cases, the I cells were reduced to complete silence, followed by a slow recovery to baseline as the spheres moved beyond detectable limits ( $\sim 3-4 \mathrm{~cm}$; Chen et al., 2005). Because E cells are the only other ELL projection neurons responding to EOD amplitude modulations, we recorded their activity in response to the same stimulus (Fig. $1 \mathrm{~B}$, bottom). As anticipated, a looming plastic sphere strongly inhibited $\mathrm{E}$ cells $(-90.24 \pm 16.28 \%)$ due to the locally decreased EOD amplitude. However, when the plastic sphere suddenly reversed its motion, strong burst responses were immediately evoked in E cells (BF: $0.18 \pm 0.09$ to $0.76 \pm 0.14$ ). Tonic spiking also contributes to the observed peak firing rates $(768.65 \pm 106.28 \%)$, which were followed by a smooth decline back to baseline levels. The increased E-cell firing rates to the receding plastic sphere occur under negative electrosensory contrast conditions; a strong violation of conventional contrast coding definitions.
As anticipated, E cells encoded the looming brass sphere with an increase in firing rate, reaching a peak of $770.82 \pm 115.13 \%$, marked by increased burst discharge (Fig. $1 C$, top; BF: $0.18 \pm$ 0.09 to $0.78 \pm 0.15)$. However, immediately upon direction reversal, $\mathrm{E}$ cells cease to discharge $(-90.85 \pm 14.01 \%)$, and their firing rates gradually climbed back to baseline levels. As shown in Figure $1 C$ (bottom), the baseline firing rate of I cells was almost completely suppressed by the looming brass sphere $(-91.97 \pm$ $15.50 \%)$, with an associated decrease in burst fraction (0.025 \pm $0.14)$. As was the case with E-cell responses to the receding plastic sphere, I cells show a switch in their preferred contrast and encode the withdrawal of the brass sphere by massively increasing their firing rate $(781.41 \pm 106.23 \%)$ and $\mathrm{BF}(0.21 \pm 0.09$ to $0.83 \pm 0.11$ ). As the brass sphere withdrew, the I-cell firing rates gradually relaxed back to baseline levels.

Although all receding motion in the environment is technically preceded by looming, an object may come to rest near the fish, and then recede at some future point. Detailed studies of electrosensory images from free-swimming A. leptorhynchus confirm their natural tendency to hover near an object and then move on (Fotowat et al., 2013). To test whether the E and I cell switches would still occur, we repeated the same motion sequence, with the exception of a pause of $7 \mathrm{~s}$ after looming, before beginning to recede. The $\mathrm{E}$ and I-cell firing rates clearly adapted during the pause period but the switch response upon motion reversal was still observed, despite the delay $(N=25$; Fig. $1 D)$. Although not acquired systematically for all cells, hold times of 1 , $2,3,5$, and $10 \mathrm{~s}$ were also tested, yielding no change in switch behavior (data not shown).

The peak firing rates experienced during looming and receding motion strongly correlate with the baseline firing rate of the cell (Fig. 2A, left). The cellular and/or network mechanisms that control the baseline firing rates of ELL pyramidal neurons are not well understood and we are presently unable to explain this correlation. In the following, this trend is significantly reduced by considering proportional changes in firing rate relative to baseline (Fig. $2 A$, right). The distributions of peak discharge rates for the $\mathrm{E}$ cells in response to looming brass and the I cells in response to looming plastic, were not significantly different (two-sample Kolmogorov-Smirnov (KS) test, $\alpha=0.05, p=0.84$ ). Likewise, the distribution of peak discharge rates of the $\mathrm{E}$ cells in response to receding plastic and the I cells in response to receding brass, were not significantly different either (two-sample KS test, $\alpha=$ $0.05, p=0.32$ ). Therefore, we grouped E- and I-cell responses together to form two categories: pyramidal cell responses to a preferred looming object and pyramidal cell responses to a conventionally, nonpreferred receding object (Fig. $2 B, C$ ). The distributions of peak firing rates for these two categories were not significantly different (two-sample KS test, $\alpha=0.05, p=0.34$ ). Effectively, the pyramidal cell responses to a nonpreferred receding object mimics the firing rate produced by that same pyramidal cell in response to the approach of a preferred object. By using both electrosensory contrast channels, a bidirectional representation of a moving object's distance is achieved. This more complex code requires switching between $\mathrm{E}$ and I-cell activity in a controlled manner, precisely at the time of direction reversal.

\section{Responses of the electroreceptor afferents to looming/receding trajectories}

Although we have shown that conventional contrast coding is insufficient for electrolocation, we still do not have a satisfying account of why this coding paradigm fails. After all, the EOD amplitude modulations are symmetric and unambiguously re- 
A

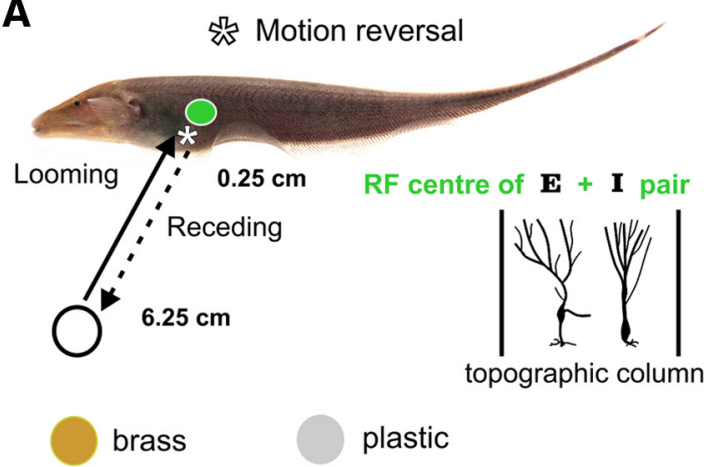

B
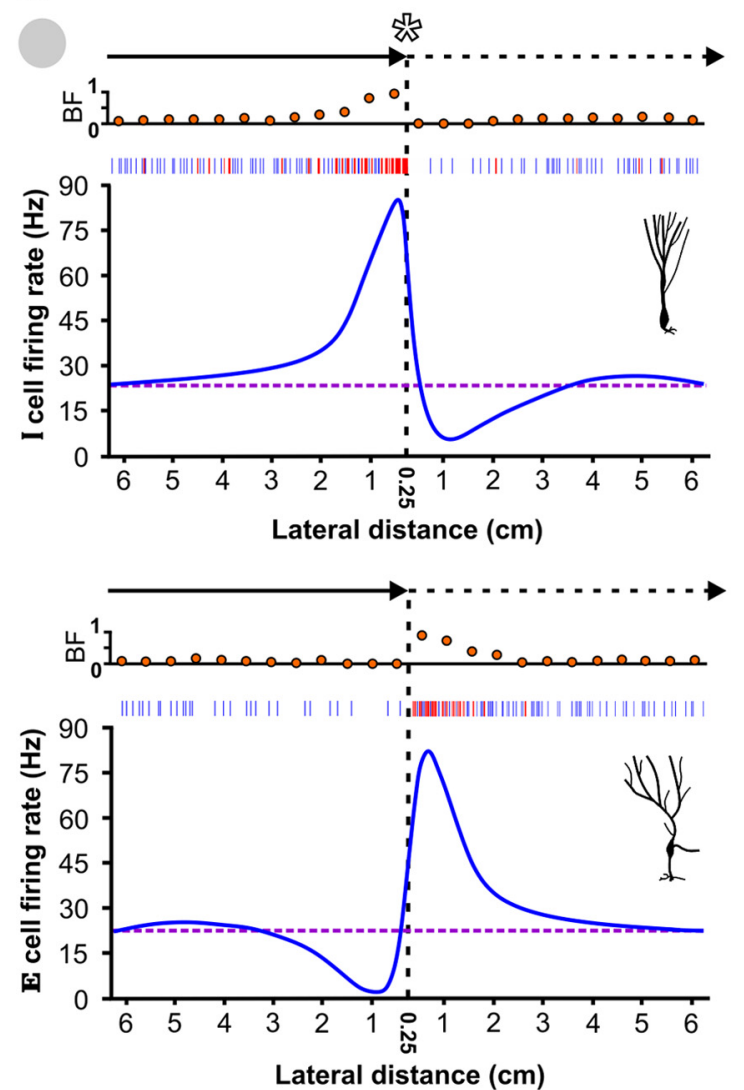

C

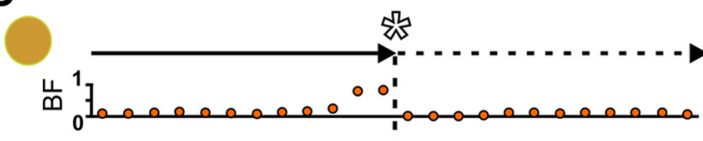

|| ||| || | || || | | || || || |||||| || || || || ||||||||||||||||| | | | || | || | | | |||| | | ||| | | || || |||

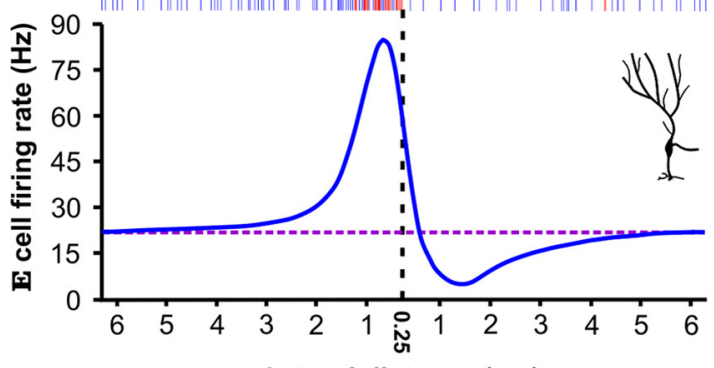

Lateral distance $(\mathrm{cm})$

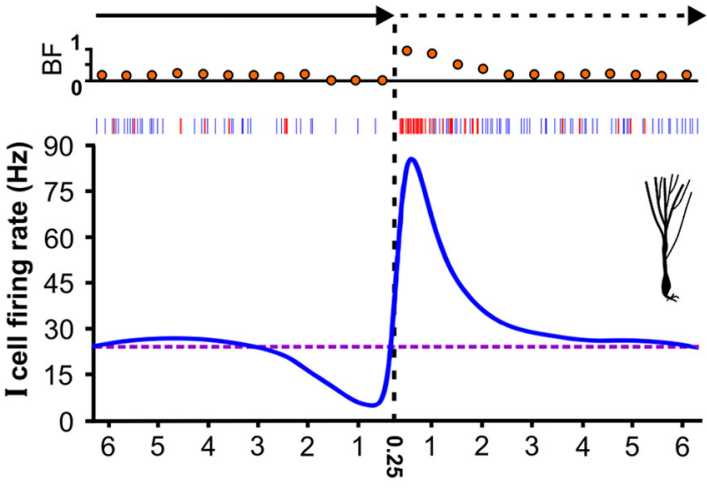

Lateral distance $(\mathrm{cm})$

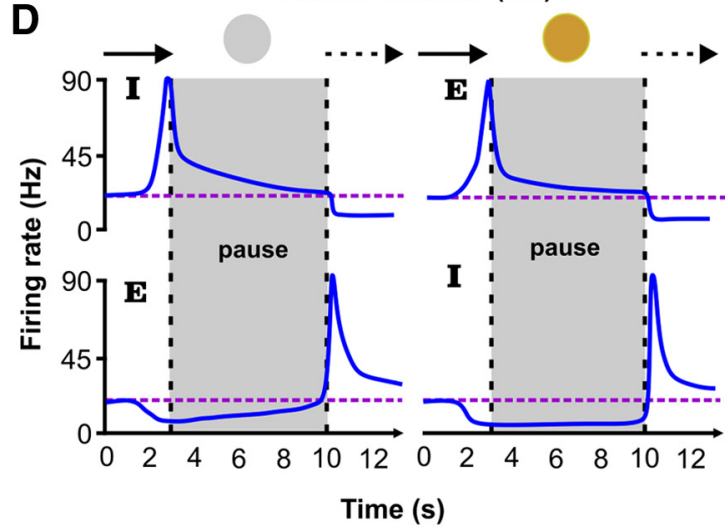

Figure 1. $\mathrm{E}(\mathrm{ON})$ and I (OFF) cells cooperatively encode object movement along the lateral body axis. $A$, The leading edge of the plastic or brass spheres start at an initial position of $6.25 \mathrm{~cm}$ from the skin and move toward the RF center of an E- and I-cell pair, stopping at $0.25 \mathrm{~cm}$. The sphere then immediately recedes back to the initial position (velocity $= \pm 2 \mathrm{~cm} / \mathrm{s}$ and acceleration $= \pm 150$ $\mathrm{cm} / \mathrm{s}^{2}$ during reversal periods). This sequence was repeated to mimic the swinging of plastic rods during a behavioral tracking experiment (Heiligenberg, 1973a,b), while we recorded in vivo from E and I cells. B, Top, As expected from static conditions and labeled line coding, the firing rate of an I cell increases as the plastic object approaches the cell's RF center. Although there are increases in both tonic (blue) and burst spiking (ISI $<10 \mathrm{~ms}$; red), the top raster plot shows that burst spikes dominate at closer range as reflected by the dramatic increase in BF. However, as the sphere reverses direction, and begins to recede from the body, the strong bursting is immediately silenced and the I-cell firing rate decreases sharply, dropping below baseline levels (purple dashed line). Note that the smoothing algorithm underestimates the peak firing rates; nevertheless, it is an effective aid for visualizing the trends. Bottom, As the plastic sphere looms toward an E cell's RF center, the firing rate is suppressed due to the local decrease in electrical contrast. As the plastic sphere withdraws, the E cell suddenly explodes into action with increased bursting and tonic spiking, despite the fact that the local sensory contrast is still negative. The E-cell firing rate gradually returns to baseline as the sphere recedes, effectively mirroring the response of the I cell during the plastic sphere approach. C, For a conducting object, like the brass sphere, we see that the E and I cells (top and bottom) switch motion coding roles. D, An object may come to rest near the fish, and then, at some future point, recede. To ensure $E$ and I cell switches still occurred, we tested the same motion sequence, but delayed receding by $7 \mathrm{~s}$ after looming. Despite the changing state of adaptation in the system, the switch responses are still observed.

flect object distance, regardless of whether it is looming or receding (Fig. $3 A, B$, top). If the electrical contrast still has the correct sign and the physical signal is bidirectionally symmetric to begin with, why does the system abandon well defined contrast labels?

Spike frequency adaptation (SFA) is present in many neuron types. There are two different forms present in the electrorecep- tor afferents, exponential and power law (Drew and Abbott, 2006). We have demonstrated that the power law form of SFA is essential for precisely encoding the changes in distance of a looming brass sphere into the firing rates of the electroreceptor afferents (Clarke et al., 2013). Since spike frequency adaptation has been shown to introduce directional selectivity in locust visual 
A
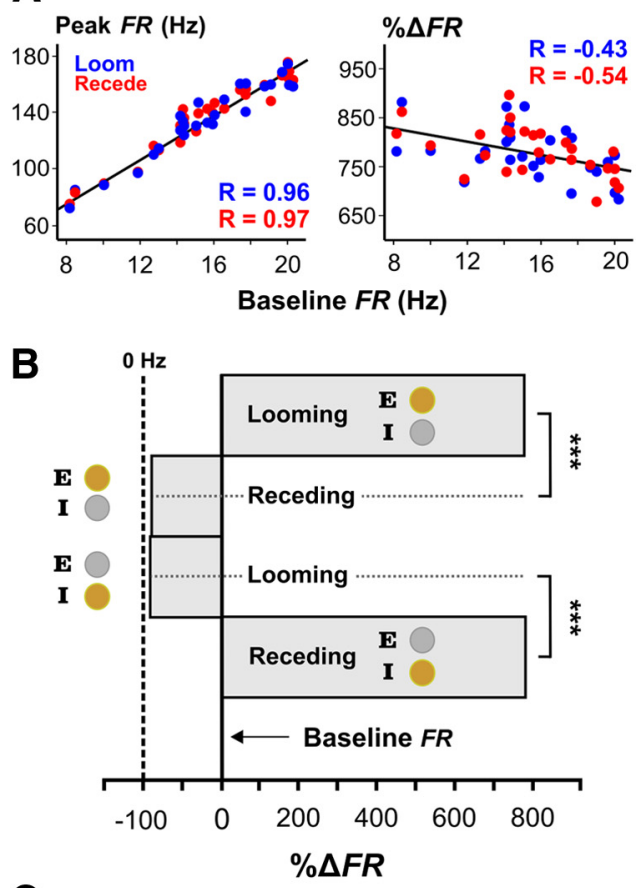

C

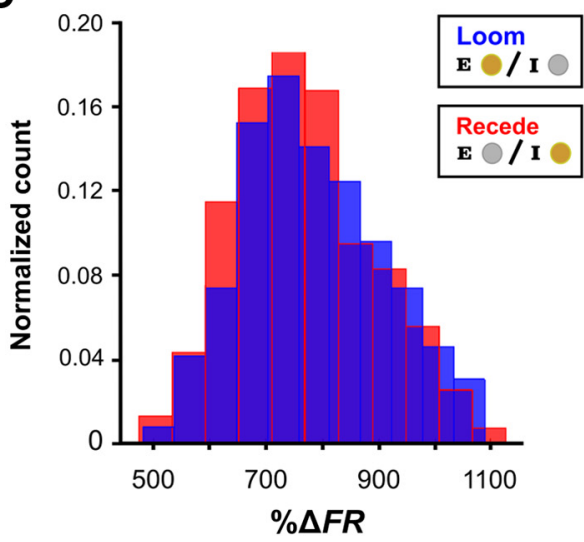

Figure 2. E- and I-cell responses to nonpreferred receding stimuli match E- and I-cell responses to preferred looming stimuli. $\boldsymbol{A}$, The averaged peak firing rates in the presence of the stimulus are plotted against baseline firing rates for each pyramidal cell (left), showing the linear relationship between these variables (correlation coefficients shown in blue and red). By considering these responses as proportional changes in firing rate relative to baseline values, we see the trend is significantly weakened (right). $\boldsymbol{B}$, The normalized responses of $\mathrm{E} / \mathrm{I}$ cells to looming brass/plastic spheres are significantly different from their responses to receding brass/ plastic spheres. Similarly, E/I-cell responses to the looming plastic/brass spheres are significantly different from their responses to the receding plastic/brass spheres. Error bars (SEM) were omitted in these graphs since the averages were done for hundreds of individual responses, with relatively small SDs compared with the mean, resulting in barely visible lines. $C$, Histogram distributions of the peak firing rates, which were measured as a normalized percentage change from baseline spiking rates. The null hypothesis that, the looming responses under conventional contrast conditions are the same as the receding responses under nonconventional contrast conditions, could not be rejected (two sample KS test, $\alpha=0.05, p=0.34$ ). These results suggest that the receding responses are a mirror of the looming responses, and that combined E/I-cell activity form the basis for a bidirectional representation of motion.

neurons (Peron and Gabbiani, 2009), we suspected that adaptive processes in the electroreceptor afferents would cause asymmetrical firing rates for looming versus receding motion. We tested and confirmed this conjecture by stimulating the electroreceptors with the same loom/recede motion profile (see Materials and Methods). Electroreceptor afferent firing rates increased dramat- ically in response to the looming brass spheres, driving strong adaption (Fig. 3A, bottom). Upon sudden withdrawal, the signal intensity diminishes; yet strong adaptation is expected to persist, suppressing the already decaying firing rate below baseline levels, reaching a minimum at $1.75 \pm 0.11 \mathrm{~cm}$. Due to the decreased spiking activity, adaptation strength subsides and the electroreceptor afferent firing rates return to baseline values. An equivalent response pattern is seen in the electroreceptor afferent responses to the looming/receding plastic sphere (Fig. $3 B$, bottom). The rate of afferent discharge decreases in response to the looming plastic sphere and adaptation strength decreases accordingly. During plastic withdrawal, the local contrast becomes less negative and the firing rate of the electroreceptor afferents increase, which is expected to momentarily overpower the reduced adaptation strength. This results in an overshoot of the baseline firing rate, which reaches a maximum at $1.77 \pm 0.09 \mathrm{~cm}$. As adaptation strength recovers, the electroreceptor afferent spiking is brought back to baseline levels. We confirmed that these skewed responses arise in a generic model of power law adaptation (Drew and Abbott, 2006), which successfully captures the looming responses of the electroreceptor afferents (Fig. $3 A, B$, bottom, insets). Although power law adaptation is essential for the formation of a well defined temporal code between firing rate and the change in looming object distance (Clarke et al., 2013), it introduces a directional asymmetry that distorts a simple distance-rate code for receding stimuli at the primary stage of sensation. This appears to be remedied in the ELL, where a symmetrical representation is assembled through the synergistic activity of ON and OFF cells.

It is difficult to envision the neural basis of the strong, nonlinear gain displayed by $\mathrm{E}$ and I cells to motion reversal. The simplest possibilities are the intrinsic bursting dynamics of ELL pyramidal cells and/or the dynamics associated with their afferent inputs (excitatory and inhibitory). Because adaptive gain control has been implicated in the anticipatory responses of ON/OFF RGCs cells to moving stimuli (Berry et al., 1999), we tested whether adaptation could explain the counter-intuitive contrast coding displayed by the electrosensory ON and OFF cells. It has been shown that E and I cells exhibit spike frequency adaptation in response to step increases or decreases in EOD amplitude respectively (Bastian and Courtright, 1991; Krahe et al., 2008). Detailed cellular analyses of this inhibition are not available but estimates of the adaptation time constants exist for the cell types used in our study (Krahe et al., 2008). From the peak, stimulus-evoked response, it was found that E cells adapted exponentially with an estimated average time constant of $200 \mathrm{~ms}$. We incorporated adaptation into an established dynamical model of a bursting E cell (Noonan et al., 2003) and used our electroreceptor afferent data as input for looming/receding simulations (see Materials and Methods). A physiological range of adaptation time constants $(\tau)$ was considered to assess the types of responses that could be expected in the population. In response to the looming brass sphere, the model shows increases in tonic and burst spiking (Fig. 3C, top), consistent with the in vivo data and the fact that the electroreceptor afferents strongly drive E-cell activity in vivo and in vitro (Berman and Maler, 1998; Bastian et al., 2002). For almost all of the adaptation values, there is a sharp cessation in the model response as the brass sphere recedes. This also resembles our in vivo data and demonstrates that the adaptive skew in afferent firing rate, coupled with adaptation in the ELL, effectively suppress E-cell output upon motion reversal. 
A

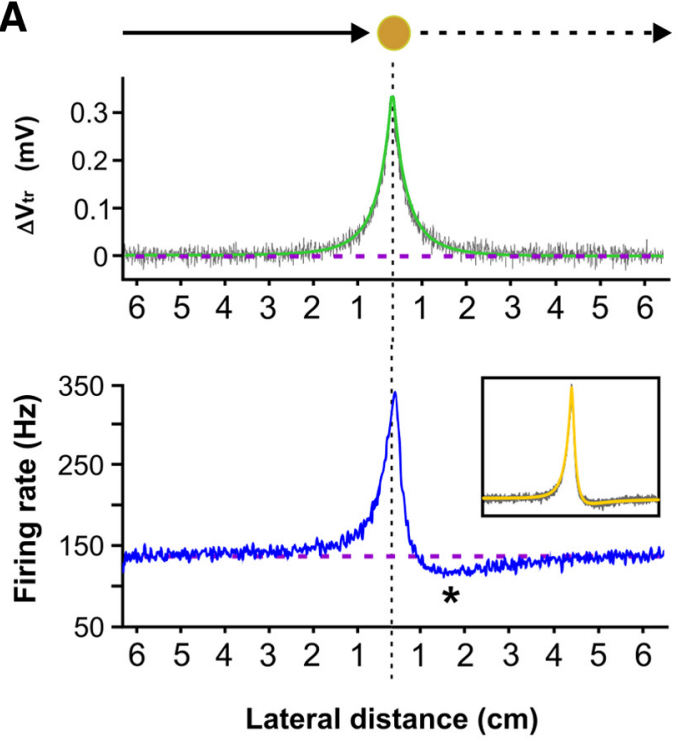

B
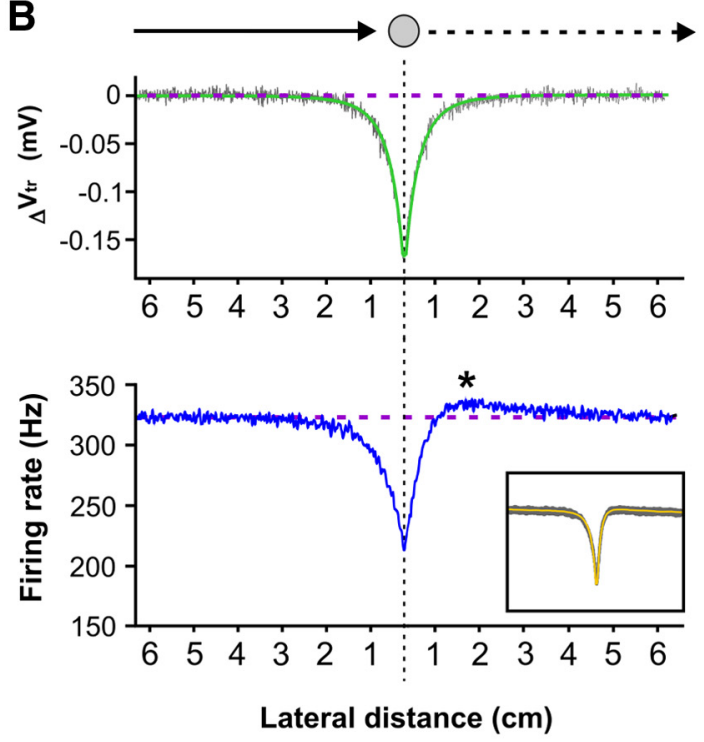
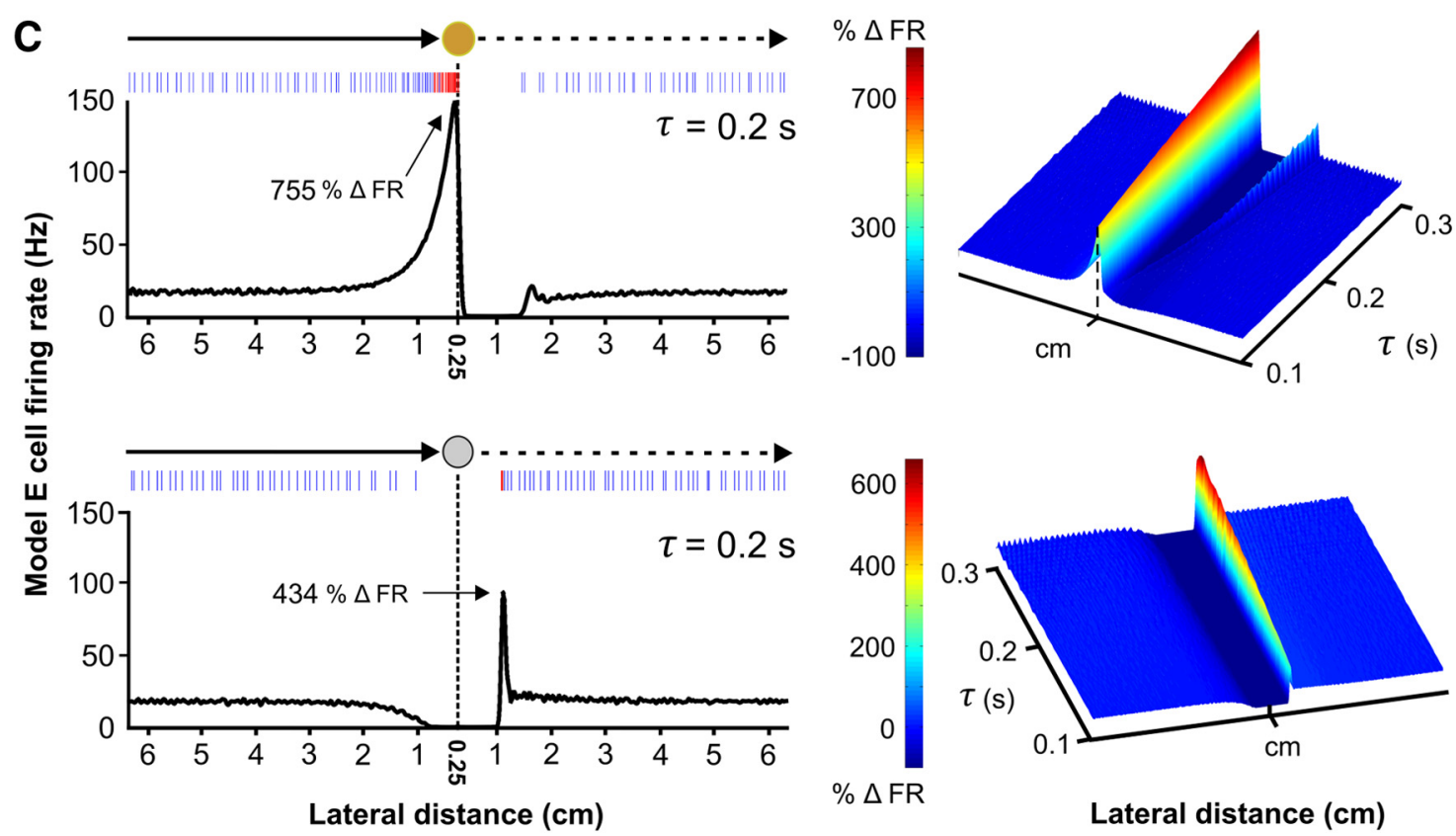

Lateral distance $(\mathrm{cm})$

Figure 3. Computation at a cost: adaptation introduces ambiguity into a simple intensity-rate code for object distance. $A$, Top, Averaged stimulus-induced change in transdermal potential $\left(\Delta V_{\mathrm{tr}}\right)$ recorded for the looming/receding brass sphere. The modeled physical signal (green) is symmetric with respect to distance (Chen et al., 2005), which we confirmed experimentally (gray). Bottom, Conversely, the averaged response of an electroreceptor afferent to the same $100 \mathrm{~m} /$ recede sequence is strongly skewed for brass withdrawal. The asterisk marks the average distance where the firing rate dropped below baseline and reached a minimum $(1.75 \pm 0.11 \mathrm{~cm})$. As shown in the boxed inset, this asymmetry is predicted by a model of power law spike frequency adaptation (yellow) which is superimposed onto many realizations of electroreceptor afferent responses (gray). Despite being essential for looming distance estimation (Clarke et al., 2013), the presence of SFA in the electroreceptor afferents prevents a well defined distance-rate code under motion reversal conditions. $\boldsymbol{B}$, Top, Averaged stimulus-induced change in transdermal potential recorded for the looming/receding plastic sphere. Bottom, The electroreceptor afferent data and the power law adaptation model show that a directional skew is also introduced for receding nonconducting objects, where the averaged position of the overshoot maximum was determined to be $1.77 \pm 0.09 \mathrm{~cm}$. C, Using our electroreceptor afferent spike train data as input, we tested whether adaptation at the level of the ELL pyramidal cells could explain the looming/receding responses observed in vivo. Simulations were performed using a previously developed bursting model (Noonan et al., 2003), to which we added a single-timescale $(\tau)$ adaptation current (Krahe et al., 2008; Materials and Methods). The model response to the looming brass resembles the in vivo data, producing strong burst discharge (see raster). Upon brass withdrawal, there is a complete suppression of the model $\mathrm{E}$-cell responses (only observed when adaptation is added to the model). At low values of $\tau$, the model Ecell fails to produce a sharp cessation in firing rate upon brass reversal and continues to discharge into the receding response, reminiscent of the skewed electroreceptor afferent firing rates (right surface plot). In response to the looming plastic sphere, the model $E$ cell shows an expected decrease in firing rate for all values of $\tau$. Upon plastic withdrawal, adaptation generates a single rebound burst (see raster) but it is delayed and fails to match the prolonged bursting and increased tonic spiking observed in our experiments for any value of $\tau$ (right surface plot). Adaptive effects are clearly an important component of E and I cell switches but are not the whole explanation. Note that adaptation introduces a slight rebound response upon recovery from brass withdrawal that is not observed in vivo.

In response to the looming plastic sphere, the model E-cell firing rate decreases, as expected from our experiments. However, as the sphere recedes, the sharp recovery of the electroreceptor afferent firing rate only generates a single, delayed burst doublet or triplet (Fig. $3 C$, bottom). This model response is very distinct from the receding responses seen in vivo, where higher peak firing rates are achieved, marked by immediate and prolonged burst spiking. Therefore, in vivo, the observed receding 

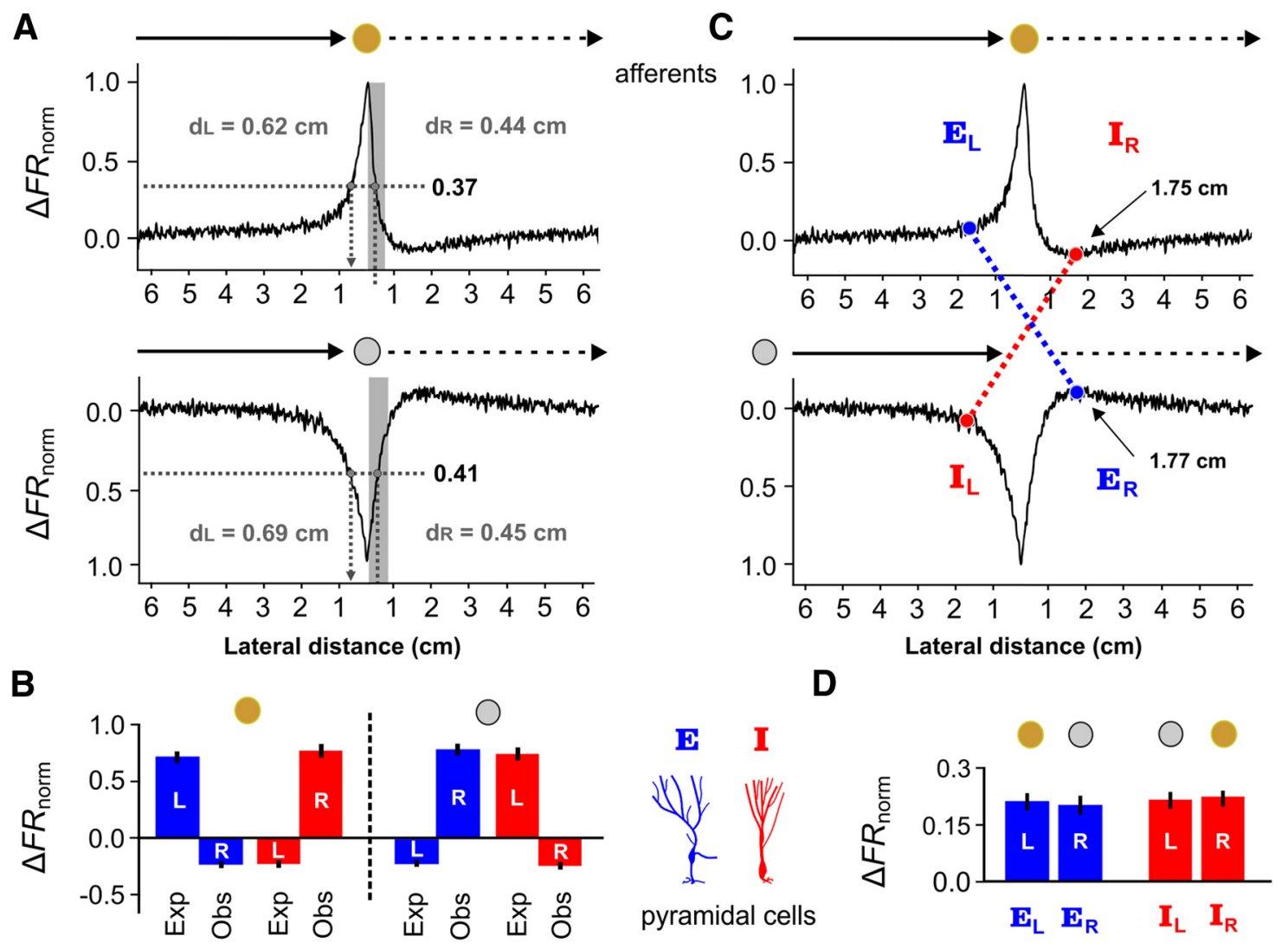

Figure 4. Electroreceptor afferent firing rates cannot fully explain $\mathrm{E}$ - and I-cell responses to receding motion. $A$, Normalized firing rates of the electroreceptor afferents $\left(\Delta F R_{\text {norm }}\right.$, $s e e$ Materials and Methods) were averaged across the first $0.5 \mathrm{~cm}$ of withdrawal, to obtain a representative value of the response to the positive contrast created by the receding brass sphere. Due to the adaptive skew in firing rate, the distances $\left(d_{L}\right.$ and $\left.d_{R}\right)$ at which this value occurred were different for the looming and receding responses. Clearly, the firing rate of an electroreceptor afferent can no longer provide an unambiguous representation of the object's position. The same procedure was repeated to obtain $d_{L}$ and $d_{R}$ for the looming/receding plastic sphere. $\boldsymbol{B}$, Next, the average responses for E cells (blue) and I cells (red) were measured at $d_{L}$ and $d_{R}$ and plotted in a bar graph ( \pm SEM) for the brass and plastic spheres. Left of dashed line: If the response of an $E$ or I cell to a receding object was driven by the electroreceptor input, then the response to a brass sphere at $d_{R}=0.44 \mathrm{~cm}$ should be the same as their response at $d_{L}=0.62 \mathrm{~cm}$. For an $\mathrm{E}$ cell (blue), the response expected from looming motion (Exp) is a substantial increase in firing rate, whereas the observed response during receding motion (Obs) is a decrease in firing rate. For an I (red) cell the expected response to the looming brass sphere is a decrease in firing rate, but its observed response to the receding brass sphere is a strong increase in firing rate. Right of dashed line, For the looming/receding plastic sphere, we compared the expected responses at $d_{L}=0.69 \mathrm{~cm}$ to the observed receding responses at $d_{R}=0.45 \mathrm{~cm}$, obtaining similar results. The observed E/I responses to the receding plastic/brass spheres are as if the local contrast was the exact opposite for the first $0.5 \mathrm{~cm}$ of receding motion, despite the fact that the electroreceptors still signal the correct sign. $C$, The skewed adaptive responses displayed by the electroreceptor afferents likely contribute to the sustained receding responses of $E$ and I cells. In response to the receding plastic sphere, the afferents produce a maximal rebound increase in firing rate at $1.77 \mathrm{~cm}$ from the skin $\left(E_{R}\right)$. We found the distance $\left(E_{L}\right)$ at which the looming brass sphere evokes the same increase in electroreceptor afferent firing rate. The crossed dashed blue line indicates the points at which the afferents provide the same increased drive to an $E$ cell. If the $E$ cell were principally driven by afferent input, then its receding response at $1.77 \mathrm{~cm}\left(E_{R}\right)$ should be equal to its looming response at $E_{L}$. Similarly, in response to a receding brass sphere, the afferents produce an under shoot in firing rate, achieving a minimum at $1.75 \mathrm{~cm}\left(I_{R}\right)$. We found the distance $\left(I_{L}\right)$ at which the looming plastic sphere evokes the same decrease in afferent firing rate. The crossed dashed red line indicates the points at which the afferents would be giving the same decreased drive to an I cell. If the I cell were mainly driven by afferent input, then its receding response at $1.75 \mathrm{~cm}\left(I_{R}\right)$ should equal to its looming response at $I_{L}$. D, These averaged pyramidal cell response values are plotted in the bar graph ( $\pm \mathrm{SEM}$ ). The responses of an $\mathrm{E}$ cell at $E_{R}$ and $E_{L}$ are nearly equal, as are the I cell responses at $I_{R}$ an $I_{L}$. This suggests that, by the time the spheres are $\sim 1.75 \mathrm{~cm}$ from the skin, the skewed electroreceptor afferent firing rates may once again contribute to the receding response in a manner consistent with the looming response.

plastic response of an E cell cannot be solely attributed to the electroreceptor afferent input, sources of pyramidal cell adaptation or the dynamics of the intrinsic burst mechanism. Additional studies are required to identify and isolate the source of the strong excitatory drive on E cells while the plastic sphere recedes.

During motion reversal, there exist an obvious contrast coding discrepancy between the stimulus-induced electrosensory contrast, the skewed electroreceptor afferent firing rates and the bidirectionally symmetric looming/receding responses displayed by the ELL pyramidal cells (Fig. 4A). For example, the electroreceptor afferents still discharge above baseline for the first $0.5 \mathrm{~cm}$ of brass sphere withdrawal, reflecting the strong positive contrast. Based on the electroreceptor afferent firing rates in response to the looming brass sphere, this should evoke strong discharge in $\mathrm{E}$ cells and inhibit I cells. However, the opposite occurs, E-cell discharge is suppressed, whereas I cells discharge vigorously, deviat- ing from the activity of the afferent inputs. For the remainder of withdrawal, adaptive skew causes the electroreceptor afferent firing rates to drop below baseline, producing an erroneous representation of negative contrast. Interestingly, this is expected to contribute to the sustained receding response in the I (OFF) channel, because by the time the receding sphere is $\sim 1.75 \mathrm{~cm}$ away from the fish, the pyramidal cell firing rates are not significantly different from the looming case (Fig. 4B). This suggests that the system returns to relying mainly on the input from the electroreceptor afferents to generate the remainder of the receding responses. Similarly, a temporary and paradoxical "relabeling" of contrast is also observed for the first $0.5 \mathrm{~cm}$ of plastic sphere withdrawal, and for distances $>1.75 \mathrm{~cm}$, the E cell responses once again appear to depend on the feedforward drive of the electroreceptor afferents. 
A

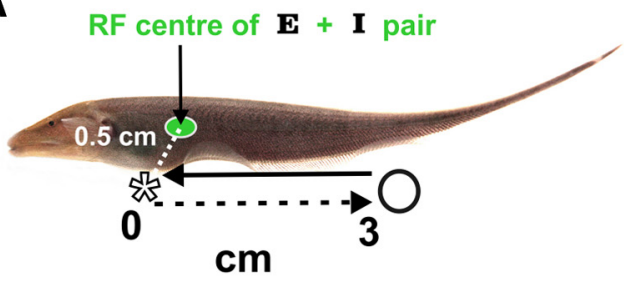

B

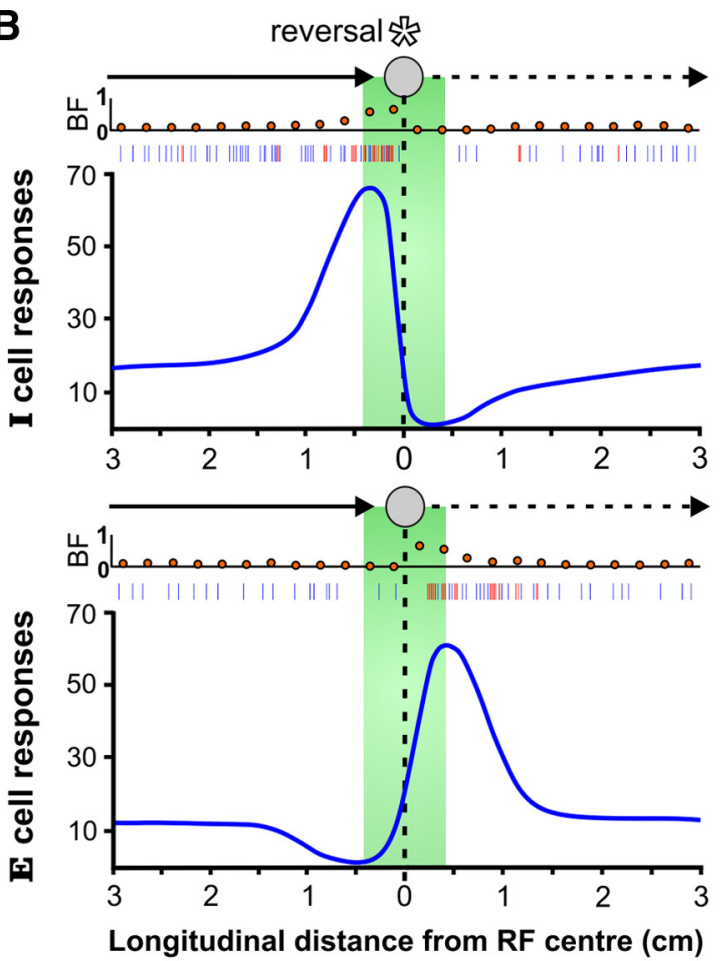

Electroreceptor afferents

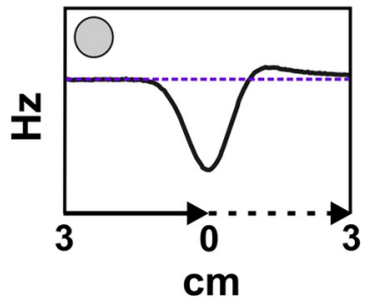

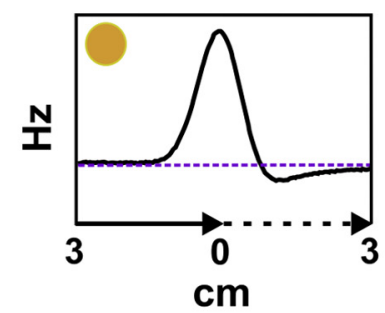

C

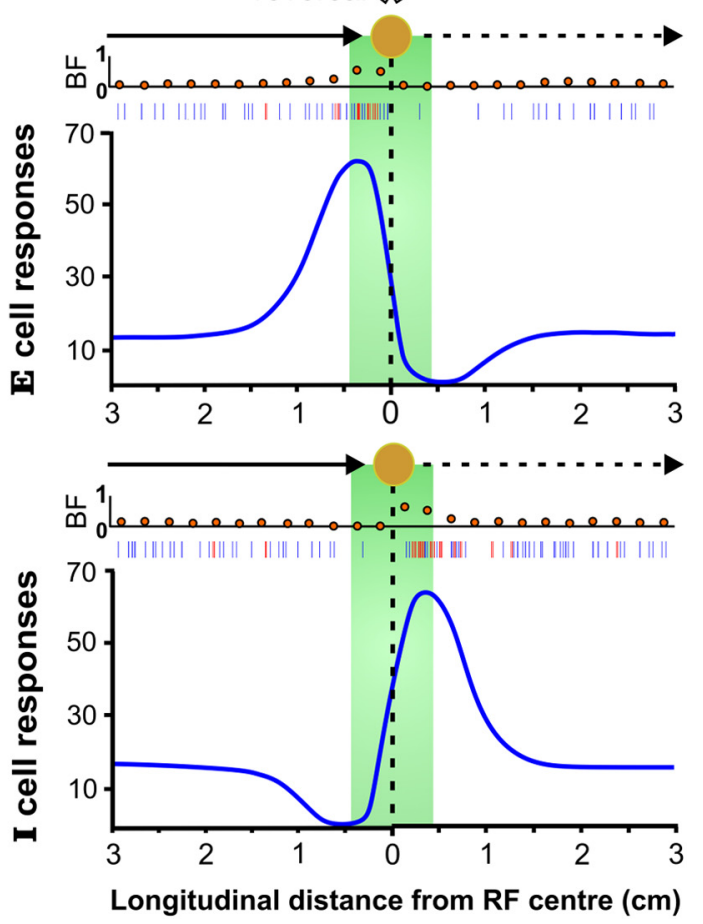

Figure 5. Eand I cells cooperatively encode object movement along trajectories parallel to the longitudinal body axis. $A$, Starting from an initial position of $3 \mathrm{~cm}$ caudal of the RF center and with the lateral axis distance fixed at $0.5 \mathrm{~cm}$, the plastic or brass sphere (not shown to scale) moves into the RF center of an E or I cell, whose spatial spread is delineated by the green shading. It then immediately moves back to the initial position (velocity $= \pm 2 \mathrm{~cm} / \mathrm{s}$ and acceleration $= \pm 150 \mathrm{~cm} / \mathrm{s}^{2}$ during reversal). This sequence was repeated to mimic a scanning behavior (Maclver et al., 2001) while we recorded in vivo from E and I cells. Insets, The predicted electroreceptor afferent model responses to the same stimulus sequences. As shown for the lateral axis, the electroreceptor firing rate is skewed after direction reversal. $\boldsymbol{B}$, As expected, the firing rate and burst fraction of I cells increased as the plastic object approached the RF center (the example spike train shows increases in tonic spikes marked in blue and burst spikes in red). When the plastic sphere reversed direction and withdrew from the RF center, the bursting ceased and I-cell firing rates decreased rapidly, dropping well below baseline levels. As the plastic sphere approached the RF center, E-cell firing rates were suppressed below spontaneous levels and the BF decreased. However, as the plastic sphere withdrew, the E cells showed marked increases in burst and tonic spiking despite the fact that, under static conditions, the cell's firing rate would be depressed. The E-cell firing rate gradually returns to baseline as the sphere recedes. $C$, The firing rate and BF of $E$ cells increased as the brass object approached their RF center. When the brass sphere reversed direction and withdrew from the RF, bursting was silenced. As the brass sphere approached the RF center, I-cell firing rates were suppressed below baseline levels and there was a marked decrease in BF. However, as the brass sphere withdrew, I cells showed large increases in spiking despite the fact that, under these contrast conditions, the firing rate should be depressed. I-cell firing rates gradually return to baseline as the brass sphere recedes. We see that E/I-cell coding switches and the patterning of burst discharge upon motion reversal, generalizes to both principal axes of motion.

\section{Responses of $\mathrm{E}$ and I cells to reversing}

\section{longitudinal trajectories}

While foraging, A. leptorhynchus often reverses its direction of motion when encountering prey (Nelson and MacIver, 1999; MacIver et al., 2001) or inanimate objects (Caputi et al., 2013). This sharp reversal will inevitably occur over the RF of some pyramidal cells. As an object approaches a RF along the longitudinal axis, the electroreceptor afferents will undergo spike rate adaptation as the signal intensity increases, such that, right after motion reversal, there is a skew in their response as the signal intensity decreases. We hypothesized that the asymmetries introduced by the electroreceptor afferents would also induce ON/ OFF switches for objects that reverse direction when moving across the sensory surface. To test this idea, we moved brass and plastic spheres longitudinally into the RF center of a cell, reversed direction and then immediately moved back out, mimicking the relative motion experienced during natural scanning behaviors (Fig. 5A). As expected, E and I cells $\left(N_{\mathrm{E}}=3, N_{\mathrm{I}}=2\right)$ responded respectively to the movement of brass and plastic spheres into their RFs with a peak firing rate of $498.14 \pm 96.04 \%$, and an associated increase in burst fraction to $0.47 \pm 0.19$. Upon direction reversal, the firing rate and the $\mathrm{BF}$ of the conventional detector immediately collapses $(-81.56 \pm 21.79 \%$; BF: $0.041 \pm$ 0.067), recovering to baseline as the object moves away (Fig. 5B). As usual, E- and I-cell firing rates are suppressed by approaching plastic and brass objects respectively $(-84.77 \pm 20.70 \%$; BF: $0.012 \pm 0.069)$. However, like the lateral axis, a moving object's reversal of direction along the longitudinal axis evoked strong 
A

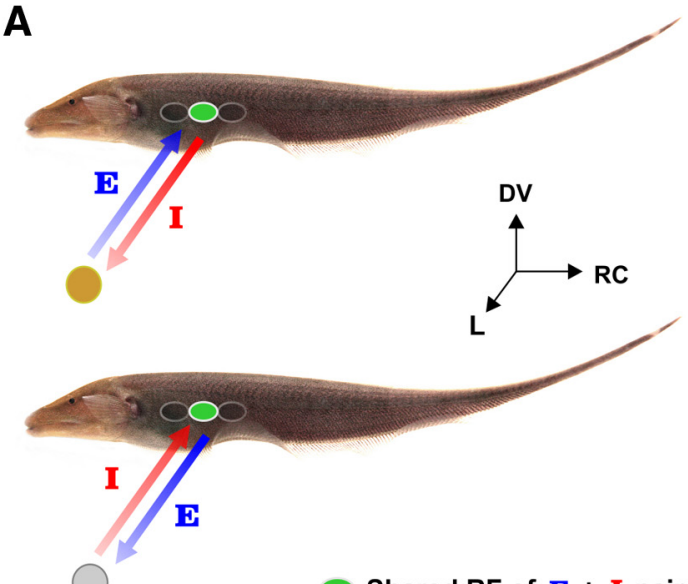

Shared RF of $\mathbf{E}+$ I pair
B
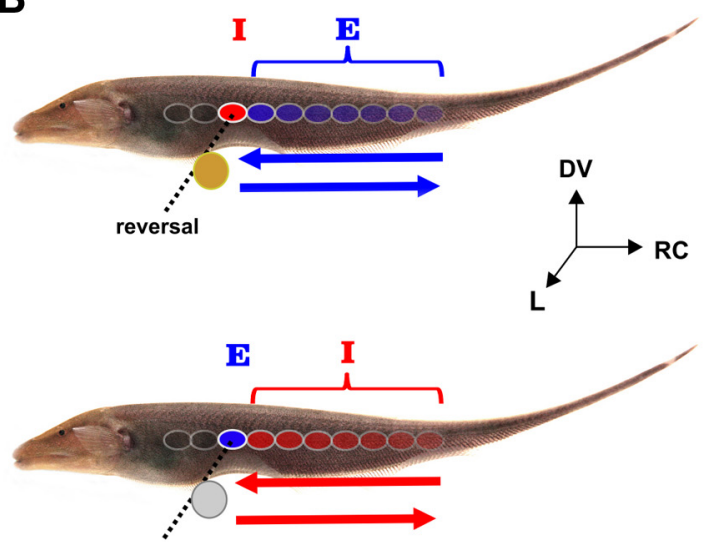
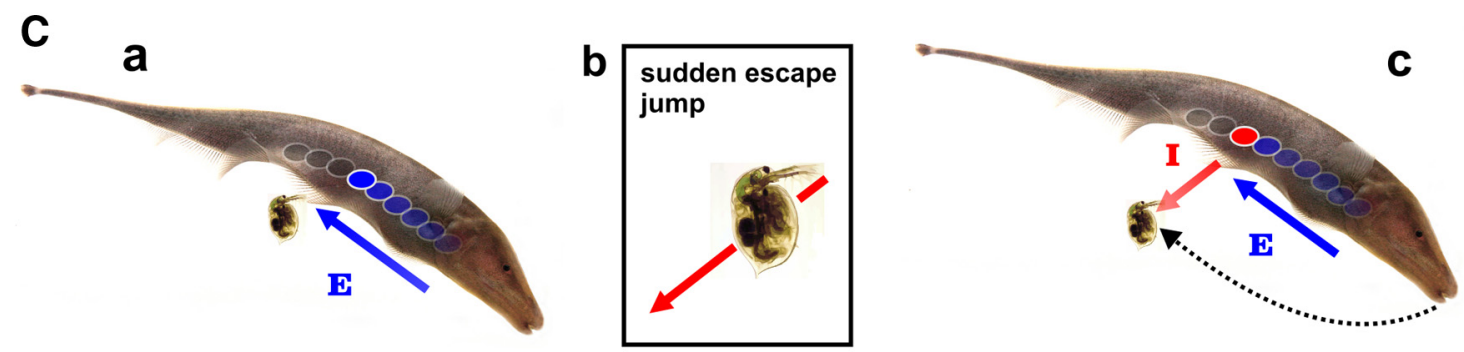

adaptive prey strike

Figure 6. Synergistic $\mathrm{E}$ - and I-cell coding paradigms for electrolocation. $A$, Top, An E cell encodes the relative distance of a looming conductive object by an increase in its firing rate and burst spiking (indicated by the shaded arrow). Upon object withdrawal along the lateral axis, E-cell activity is suppressed, whereas the I cell encodes the motion of the brass sphere. Bottom, An I cell encodes the looming nonconductive object by increasing its firing rate and burst spiking. However, as the nonconducting object recedes, I cells are suppressed and $E$ cells encode the receding brass sphere. B, Top, As these fish scan past conducting objects in their environment, their relative motion causes local positive contrast to move across the body surface (rostrocaudal and dorsoventral plane). This will evoke discharge in a topographic sequence of sequentially activated $E$ cells (RF shading represents the sequence of activation). At the point of direction reversal, the firing rate of the E cell is suppressed and strong bursting is evoked in the I cells within that same topographic column. As the object moves in the reverse direction, an E-cell representation may progressively return. Bottom, As a nonconducting object moves into the RF of an I cell there is an increase in firing rate and BF. If the object's trajectory suddenly reverses, then the suppressed $\mathrm{E}$ cell responds to the withdrawal, whereas the I cell goes silent. C, We illustrate the expected responses of E and I cells during a documented prey capture sequence (Maclver et al., 2001, their Fig. 13). Ca, While scanning its environment, a fish swims forward, past a Daphnia (water flea). This conductive organism will evoke discharge in a topographic sequence ofE cells as indicated by the arrow. $\boldsymbol{C} \boldsymbol{b}$, Between the time of prey detection and capture, the Daphnia will sometimes make an escape jump (0'Keefe et al., 1998). Cc, The conductive organism is now receding from the fish's body and is expected to evoke a response in the I cells, whose activity represents the body location from where the Daphnia is receding and whose decreasing firing rate measures its displacement. Meanwhile E-cell discharge in the same ELL column will be suppressed. In this instance, gymnotiform fish often perform an adaptive strike to capture the prey, where estimation of the prey's location now appears to be predictively encoded by the firing rate of the OFF channel.

responses in the opposing contrast detectors $(487.49 \pm 87.02 \%$, BF: $0.50 \pm 0.20)$ and an abandonment of conventional contrast coding.

We summarize the E/I-cell responses to looming/receding and longitudinal movements (Fig. 6A,B). We have shown that $E$ and I cells respond with strong burst discharge to looming brass and plastic spheres respectively as well as to longitudinal movement of these spheres into their RFs, which is entirely expected based on extensive anatomical data (Maler et al., 1981; Maler and Mugnaini, 1994; Wang and Maler, 1997), in vitro electrophysiology (Berman and Maler, 1998), in vivo responses to receptive field stimulation (Bastian et al., 2002) and longitudinal motion signals (Bastian, 1981; Chacron et al., 2009). Despite the fact that the local electrical contrast has the wrong sign according to ON/OFF cell definitions, both $\mathrm{E}$ and I cells respond vigorously to motion reversal of the plastic and brass spheres respectively (Fig. 6A, B). A likely implication of these E/I-cell switches for natural predatory behavior is illustrated in Figure 6C. While scanning past a Daphnia (water flea and staple prey), it can suddenly jump away, requiring the fish to perform an adaptive strike (MacIver et al., 2001). As the fish initially swims alongside a Daphnia, the relative longitudinal motion creates a positive contrast pattern that activates a topographic sequence of E cells and suppresses I cells. However, if a Daphnia suddenly jerks back to avoid capture, its receding motion will recruit I cells, whose activity signal a sudden withdrawal and presumably guide an appropriate prey capture response. The fish's rapid recalibration of movement to capture its target suggests an important neuroethological role for E/I pyramidal cell switches, both as a salient cue and as a means to estimate stimulus motion parameters.

\section{Discussion}

We have shown that $\mathrm{E}$ and I cells cooperatively produce a firing rate representation of a moving object's position that is symmetric under reversal of motion direction; this was observed for two principal electrolocation axes (Figs. 1, 5).

Simulations with our E-cell model demonstrate that the electroreceptor afferent firing rates and intrinsic burst dynamics principally determine the responses of E cells to looming motion in their RFs. Yet, these mechanisms were unable to account for the receding responses that effectively mirror the encoding of distance information observed during looming, despite the clear 
departure from the afferent firing rates and expected physiology (Figs. 3C, 4). We hypothesize that a central mechanism recreates the looming distance rate code to accurately estimate the location of the receding sphere for lateral distances $<1.75 \mathrm{~cm}$. Therefore, the receding responses of the pyramidal cells may be a form of predictive coding, similar in purpose to the anticipatory responses seen in retinal ganglion cells to moving stimuli (Berry et al., 1999; Münch et al., 2009). The critical question becomes: what are the neural mechanisms that generate these surprising departures from conventional contrast coding?

\section{Physiological mechanisms of the receding response}

We have shown that empirically motivated SFA is enough to suppress the E-cell model response to the receding brass sphere when coupled with the adaptive skew present in the electroreceptor afferent firing rates (Fig. $3 C$ ). The source of this pyramidal cell adaptation is currently unknown. Afferent synaptic depression is unlikely because it recovers far too rapidly ( $<8 \mathrm{~ms}$; Khanbabaie et al., 2010). Instead, we expect that the source is disynaptic inhibition, mediated by GABAergic interneurons activating GABA-A receptors (Maler and Mugnaini, 1994; Berman and Maler, 1998). Shumway and Maler (1989) have directly shown that pyramidal cell SFA is greatly reduced after blockade of GABA-transmission and there is a strong correlation between the extent of GABAergic innervation of pyramidal cells and the extent of SFA (Bastian and Courtright, 1991; Maler and Mugnaini, 1994). Furthermore, brief stimulation of the electroreceptor afferents can induce strong GABA-A mediated shunting inhibition that outlasts the stimulus by hundreds of $\mathrm{ms}$ and is due to sustained interneuron discharge (Berman and Maler, 1998). Therefore, we suspect that the afferent-driven discharge of GABAergic interneurons evoked by the looming brass sphere will persist after motion reversal, accounting for the observed suppression.

In the case of the receding plastic sphere, the dynamics of the electroreceptor afferents, the intrinsic bursting mechanism and the adaptation of ELL pyramidal cells are all incapable of reproducing the in vivo responses of E cells. The physiological mechanisms that generate the reflections of a looming response in the opposing contrast detector are of great interest but are beyond the scope of this paper. Clearly, the switches rely further on the nonlinear dynamics of the ELL network (Chacron, 2006) and/or its feedback input (Bratton and Bastian, 1990), to control the coordinated and paradoxical contrast coding displayed by the electrosensory ON/OFF cells.

\section{Importance of the receding response}

The pyramidal cells of the ELL project to the torus semicircularis (TS), a mid-brain structure that projects to the optic tectum (Krahe and Maler, 2014). A subset of TS cells display strong directional selectivity for longitudinal motion and sparse representations of electrosensory signals emerge in this nucleus (Chacron et al., 2011; Khosravi-Hashemi et al., 2011). Therefore, we hypothesize that there will be looming and receding specific cells in the midbrain (TS and/or tectum) that operate on both $\mathrm{E}$ and I channels to guide the tectal control of movement. Consistent with this hypothesis, responses to looming stimuli have been described in the early stages of locust vision (Fotowat and Gabbiani, 2011) and throughout the visual pathway of vertebrates (Sakata et al., 1983; Sun and Frost, 1998; Münch et al., 2009; Nakagawa and Hongjian, 2010). Responses to receding stimuli have been recorded in the optic tectum of barn owls (Zahar et al., 2012) and there are pigeon midbrain neurons that are selective for either the expansion (looming) or contraction (receding) of illumination patterns on the retina (Wang et al., 1993). Spare representations of motion appear in the posterior parietal cortex of rhesus monkeys, where a fraction of the motion-sensitive neurons respond selectively to receding stimuli (Sakata et al., 1983). Neurons sensitive to looming and receding acoustic stimuli have also been reported in primate cortex (Maier and Ghazanfar, 2007). All of these results confirm the intuitive idea that sparse representations of motion direction are important to higher levels of processing, not only in the electrosense, but in vision and audition as well.

Can sequences of ON and OFF RGC activity initiate representations of motion direction from dynamic contrast patterns? Does adaptive skew in the visual system necessitate ON/OFF switches when stimulus intensity changes from increasing to decreasing (or vice versa)? In the vertebrate retina, it has been noted that adaptation can reverse a RGC's directional selectivity (Rivlin-Etzion et al., 2012). Furthermore, it has been shown that longitudinal motion reversal produces burst discharge in RGCs, which is expected to reset downstream networks so that the motion patterns preceding the reversal event do not contaminate future estimates (Schwartz et al., 2007). This interpretation extends nicely to the electrosense, where SFA in the electroreceptor afferents generates errors in an otherwise simple intensity-rate code and the system abandons its well defined contrast channels. Schwartz et al. (2007) did not identify the cells as ON or OFF types, or address whether conventional contrast coding breaks down. Exploring this possibility may reveal deeper parallels between the electrosensory and visual systems. Interestingly, there exists a documented case of OFF cells in the salamander retina transiently responding $(\sim 100 \mathrm{~ms})$ to positive contrast as if they were ON cells (Geffen et al., 2007) but a switch from ON to OFF was not observed. In the electrosense, we have shown that contrast relabeling occurs from $\mathrm{OFF}$ to $\mathrm{ON}$, as well as from $\mathrm{ON}$ to OFF, where the relabeled lines can persist on the order of seconds. This raises the possibility that, in addition to burst spiking acting as a salient cue, coordinated ON/OFF cell activity may also be involved in the sustained encoding of visual information over longer timescales. In support of this idea, it has recently been proposed that olfactory cortex pyramidal neurons can "read out" sequential patterns of activation across a population of their mitral/tufted cell afferent inputs (Haddad et al., 2013). Therefore, monitoring sequences of activation across distinct neuron populations may be a common neural strategy to extract additional information about a stimulus that is not contained directly within the spiking responses of the individual cell types.

\section{Decoding looming and receding motion}

An unexpected result of our experiments was the apparent disconnect between the response of ELL pyramidal cells and the afferent inputs (Figs. 3, 4). Looming responses are consistent with contrast coding definitions, behaving in accordance with the afferent input and intrinsic pyramidal cell dynamics. However, there is significant deviation from these mechanisms during receding motion. At the population level, these responses to receding motion are monotonically decreasing functions of distance and encode changes in object location in a way that is compatible with looming responses, even though the afferent input is no longer concordant with the physical stimulus and the electrical contrast is the opposite sign. Our results demonstrate that a decoder cannot exclusively rely on the instantaneous firing rates of either E or I cells to encode bidirectional motion. Although the suppression of a pyramidal cell's firing rate signals motion reversal, it does not provide an invertible mapping of the receding 
stimulus' position and could not provide unambiguous estimates of object location. Instead, a distance-rate code is distributed over both cell types, implying that E- and I-cell outputs cannot be mapped into distinct channels for encoding object location. As a result, the electrosensory ON/OFF cells can no longer be used to unequivocally signal electrical contrast information. In other words, the classic notion of "labeled line contrast coding" is inadequate; a downstream decoder must combine $\mathrm{ON}$ and OFF cell responses in a more flexible manner.

It has been previously suggested that veridical encoding of contrast information is too restrictive to permit visual constancy in a complex environment (Purves et al., 2011). We have shown that maintaining perceptual constancy during contextual changes is even a problem for the relatively simple electrosense and is expected to be accomplished by a putative decoder that monitors patterns of activity across distinct population subsets. Given the similarities between low level electrosensory and visual processing, it should prove interesting to explore cooperative ON and OFF cell coding under different conditions of optic flow (Frost and Nakayama, 1983), where moving contrast edges are created by expanding and contracting illumination patterns that shift across the retina. The design of neural prosthetics and brain/machine interfaces should benefit from the discovery of neural circuits responsible for extracting semantic information (like motion direction) from temporal activity patterns that are distributed over heterogeneous neuron populations.

\section{References}

Bastian J (1981) Electrolocation: II. The effects of moving objects and other electrical stimuli on the activities of two categories of posterior lateral line lobe cells in Apteronotus albifrons. J Comp Physiol A Neuroethol Sens Neural Behav Physiol 144:481-494. CrossRef

Bastian J, Courtright J (1991) Morphological correlates of pyramidal cell adaptation rate in the electrosensory lateral line lobe of weakly electric fish. J Comp Physiol A 168:393-407. CrossRef Medline

Bastian J, Chacron MJ, Maler L (2002) Receptive field organization determines pyramidal cell stimulus-encoding capability and spatial stimulus selectivity. J Neurosci 22:4577-4590. Medline

Berman NJ, Maler L (1998) Inhibition evoked from primary afferents in the electrosensory lateral line lobe of the weakly electric fish (Apteronotus leptorhynchus). J Neurophysiol 80:3173-3196. Medline

Berry MJ 2nd, Brivanlou IH, Jordan TA, Meister M (1999) Anticipation of moving stimuli by the retina. Nature 398:334-338. CrossRef Medline

Bratton B, Bastian J (1990) Descending control of electroreception: II. Properties of nucleus praeeminentialis neurons projecting directly to the electrosensory lateral line lobe. J Neurosci 10:1241-1253. Medline

Caputi AA, Aguilera PA, Carolina Pereira A, Rodríguez-Cattáneo A (2013) On the haptic nature of the active electric sense of fish. Brain Res 1536: 27-43. CrossRef Medline

Chacron MJ (2006) Nonlinear information processing in a model sensory system. J Neurophysiol 95:2933-2946. CrossRef Medline

Chacron MJ, Toporikova N, Fortune ES (2009) Differences in the time course of short-term depression across receptive fields are correlated with directional selectivity in electrosensory neurons. J Neurophysiol 102: 3270-3279. CrossRef Medline

Chacron MJ, Longtin A, Maler L (2011) Efficient computation via sparse coding in electrosensory neural networks. Curr Opin Neurobiol 21:752760. CrossRef Medline

Chen L, House JL, Krahe R, Nelson ME (2005) Modeling signal and background components of electrosensory scenes. J Comp Physiol A Neuroethol Sens Neural Behav Physiol 191:331-345. CrossRef Medline

Clarke SE, Naud R, Longtin A, Maler L (2013) Speed-invariant encoding of looming object distance requires power law spike rate adaptation. Proc Natl Acad Sci U S A 110:13624-13629. CrossRef Medline

Drew PJ, Abbott LF (2006) Models and properties of power-law adaptation in neural systems. J Neurophysiol 96:826-833. CrossRef Medline
Fotowat H, Gabbiani F (2011) Collision detection as a model for sensorymotor integration. Annu Rev Neurosci 34:1-19. CrossRef Medline

Fotowat H, Harrison RR, Krahe R (2013) Statistics of the electrosensory input in the freely swimming weakly electric fish Apteronotus leptorhynchus. J Neurosci 33:13758-13772. CrossRef Medline

Frost BJ, Nakayama K (1983) Single visual neurons code opposing motion independent of direction. Science 220:744-745. CrossRef Medline

Geffen MN, de Vries SE, Meister M (2007) Retinal ganglion cells can rapidly change polarity from off to on. PLoS Biol 5:e65. CrossRef Medline

Haddad R, Lanjuin A, Madisen L, Zeng H, Murthy VN, Uchida N (2013) Olfactory cortical neurons read out a relative time code in the olfactory bulb. Nat Neurosci 16:949-957. CrossRef Medline

Heiligenberg W (1973a) "Electromotor" response in the electric fish eigenmannia (Rhamphichthyidae, gymnotoidei). Nature 243:301-302. CrossRef

Heiligenberg W (1973b) Electrolocation of objects in the electric fish eigenmannia (Rhamphichthyidae, gymnotoidei). J Comp Physiol 87:137-164. CrossRef

Joesch M, Schnell B, Raghu SV, Reiff DF, Borst A (2010) ON and OFF pathways in Drosophila motion vision. Nature 468:300-304. CrossRef Medline

Khanbabaie R, Nesse WH, Longtin A, Maler L (2010) Kinetics of fast shortterm depression are matched to spike train statistics to reduce noise. J Neurophysiol 103:3337-3348. CrossRef Medline

Khosravi-Hashemi N, Fortune ES, Chacron MJ (2011) Coding movement direction by burst firing in electrosensory neurons. J Neurophysiol 106: 1954-1968. CrossRef Medline

Krahe R, Gabbiani F (2004) Burst firing in sensory systems. Nat Rev Neurosci 5:13-23. CrossRef Medline

Krahe R, Maler L (2014) Neural maps in the electrosensory system of weakly electric fish. Curr Opin Neurobiol 24C:13-21. CrossRef Medline

Krahe R, Bastian J, Chacron MJ (2008) Temporal processing across multiple topographic maps in the electrosensory system. J Neurophysiol 100:852867. CrossRef Medline

Lockery SR (2011) The computational worm: spatial orientation and its neuronal basis in C. elegans. Curr Opin Neurobiol 21:782-790. CrossRef Medline

MacIver MA, Sharabash NM, Nelson ME (2001) Prey-capture behavior in gymnotid electric fish: motion analysis and effects of water conductivity. J Exp Biol 204:543-557. Medline

Maier JX, Ghazanfar AA (2007) Looming biases in monkey auditory cortex. J Neurosci 27:4093-4100. CrossRef Medline

Maler L (2009) Receptive field organization across multiple electrosensory maps: I. Columnar organization and estimation of receptive field size. J Comp Neurol 516:376-393. CrossRef Medline

Maler L, Mugnaini E (1994) Correlating gamma-aminobutyric acidergic circuits and sensory function in the electrosensory lateral line lobe of a gymnotiform fish. J Comp Neurol 345:224-252. CrossRef Medline

Maler L, Sas EK, Rogers J (1981) The cytology of the posterior lateral line lobe of high-frequency weakly electric fish (gymnotidae): dendritic differentiation and synaptic specificity in a simple cortex. J Comp Neurol 195:87-139. CrossRef Medline

Marsat G, Proville RD, Maler L (2009) Transient signals trigger synchronous bursts in an identified population of neurons. J Neurophysiol 102: 714-723. CrossRef Medline

Münch TA, da Silveira RA, Siegert S, Viney TJ, Awatramani GB, Roska B (2009) Approach sensitivity in the retina processed by a multifunctional neural circuit. Nat Neurosci 12:1308-1316. CrossRef Medline

Nakagawa H, Hongjian K (2010) Collision-sensitive neurons in the optic tectum of the bullfrog, Rana catesbeiana. J Neurophysiol 104:2487-2499. CrossRef Medline

Nelson ME, MacIver MA (1999) Prey capture in the weakly electric fish Apteronotus albifrons: sensory acquisition strategies and electrosensory consequences. J Exp Biol 202:1195-1203. Medline

Noonan L, Doiron B, Laing C, Longtin A, Turner RW (2003) A dynamic dendritic refractory period regulates burst discharge in the electrosensory lobe of weakly electric fish. J Neurosci 23:1524-1534. Medline

O'Keefe TC, Brewer MC, Dodson SI (1998) Swimming behavior of daphnia: its role in determining predation risk. J Plankton Res 20:973-984. CrossRef

Oswald AM, Chacron MJ, Doiron B, Bastian J, Maler L (2004) Parallel processing of sensory input by bursts and isolated spikes. J Neurosci 24:43514362. CrossRef Medline 
Peron S, Gabbiani F (2009) Spike frequency adaptation mediates looming stimulus selectivity in a collision-detecting neuron. Nat Neurosci 12:318326. CrossRef Medline

Purves D, Wojtach WT, Lotto RB (2011) Understanding vision in wholly empirical terms. Proc Natl Acad Sci U S A 108:15588-15595. CrossRef Medline

Rivlin-Etzion M, Wei W, Feller MB (2012) Visual stimulation reverses the directional preference of direction-selective retinal ganglion cells. Neuron 76:518-525. CrossRef Medline

Sakata H, Shibutani H, Kawano K (1983) Functional properties of visual tracking neurons in posterior parietal association cortex of the monkey. J Neurophysiol 49:1364-1380. Medline

Schiller PH (1992) The ON and OFF channels of the visual system. Trends Neurosci 15:86-92. CrossRef Medline

Schwartz G, Taylor S, Fisher C, Harris R, Berry MJ 2nd (2007) Synchronized firing among retinal ganglion cells signals motion reversal. Neuron 55: 958-969. CrossRef Medline

Shimazaki H, Shinomoto S (2010) Kernel bandwidth optimization in spike rate estimation. J Comput Neurosci 29:171-182. CrossRef Medline
Shumway CA, Maler L (1989) GABAergic inhibition shapes temporal and spatial response properties of pyramidal cells in the electrosensory lateral line lobe of gymnotiform fish. J Comp Physiol A 164:391-407. CrossRef Medline

Sun H, Frost BJ (1998) Computation of different optical variables of looming objects in pigeon nucleus rotundus neurons. Nat Neurosci 1:296-303. CrossRef Medline

Tian B, Kuśmierek P, Rauschecker JP (2013) Analogues of simple and complex cells in rhesus monkey auditory cortex. Proc Natl Acad Sci U S A 110:7892-7897. CrossRef Medline

Wang D, Maler L (1997) In vitro plasticity of the direct feedback pathway in the electrosensory system of Apteronotus leptorhynchus. J Neurophysiol 78:1882-1889. Medline

Wang YC, Jiang S, Frost BJ (1993) Visual processing in pigeon nucleus rotundus: luminance, color, motion, and looming subdivisions. Vis Neurosci 10:21-30. CrossRef Medline

Zahar Y, Wagner H, Gutfreund Y (2012) Responses of tectal neurons to contrasting stimuli: an electrophysiological study in the barn owl. PloS One 7:e39559. CrossRef Medline 